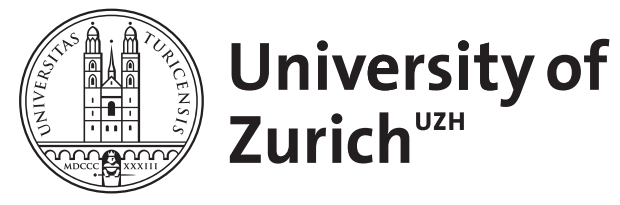

Zurich Open Repository and Archive

University of Zurich

University Library

Strickhofstrasse 39

CH-8057 Zurich

www.zora.uzh.ch

Year: 2016

\title{
Socioeconomic Status Differences in Negative Emotions
}

Jakoby, Nina

DOI: https://doi.org/10.5153/sro.3895

Posted at the Zurich Open Repository and Archive, University of Zurich

ZORA URL: https://doi.org/10.5167/uzh-130208

Journal Article

Originally published at:

Jakoby, Nina (2016). Socioeconomic Status Differences in Negative Emotions. Sociological Research Online, 21(2):1-10.

DOI: https://doi.org/10.5153/sro.3895 


\title{
Socioeconomic Status Differences in Negative Emotions
}

\author{
by Nina Jakoby \\ University of Zurich
}

Sociological Research Online, 21 (2), 6

<http://www.socresonline.org.uk/21/2/6.html>

DOI: $10.5153 /$ sro. 3895

Received: 2 Nov 2015 | Accepted: 15 Mar 2016 | Published: 31 May 2016

\begin{abstract}
The frequency of the experience of particular emotions can be considered a measure of subjective well-being and therefore an indicator of the quality of life in the overall population. Key approaches to the sociology of emotions provide the theoretical background to this study. On the basis of Swiss Household Panel (SHP) data for the years 2005-2011, a random effects regression assessed relationships between the frequency of negative emotions (desperation, anxiety and depression) and the parameters of individual socioeconomic status. The results suggest that negative emotions are experienced differently along status- and resource-based predictors such as education, income and occupational status. These associations persist when controlling for key variables of mental health and stress research such as critical life events, chronic stressors and social resources.
\end{abstract}

Keywords: Emotion, Depression, Anxiety, Social Inequality, Socioeconomic Status, Social Class

\section{Introduction $^{[1]}$}

1.1 The social stratification of wealth, power and status is a topic at the heart of sociology. Nevertheless, sociological inquiry has often neglected the emotional consequences of objective living conditions. The frequency of the experience of particular emotions can be considered a measure of subjective well-being and therefore an indicator of the quality of life in the overall population (Yang 2008). Anxiety and depression, in particular, represent two major forms of psychological distress and 'uncomfortable subjective states' (Mirowsky and Ross 1986: 24) that are closely connected. Anxiety includes feelings of fear or concern, whereas depression involves feelings of sadness, worthlessness or hopelessness (Mirowsky and Ross 1986). ${ }^{[2]}$ The social gradient in various mental health disorders is well documented (e.g., Matthews and Gallo 2011; Aneshensel et al. 1991; Murphy et al. 1991; Ritsher et al. 2001; Yu and Williams 2006). Much less attention has been paid to socioeconomic status differences in experiencing 'everyday emotions' (Thoits 1989: 322) based on self-reports, rather than psychiatric diagnoses (Horwitz 2013; Horwitz and Wakefield 2007). Correlates of specific emotions such as anxiety, sadness or anger have recently been investigated in the field of the sociology of emotions (e.g., Simon and Nath 2004; Simon and Lively 2010; Jakoby 2013; Rackow et al. 2012). However, quantitative studies on emotional inequality are 
still rare. Turner and Stets (2005: 293) have indicated that 'only tentative steps have been taken in sorting out the (...) relationship between social structure and emotional arousal.' Thus social structure can be analysed as a system of status and resource positions (Turner and Stets 2005). Furthermore, Schieman (2006) has pointed out that sociology has failed to link emotions to mental health research. The present article aims to address these limitations by analysing the association between status- and resource-based indicators of SES (Matthews and Gallo 2011) and the frequency of negative emotions (desperation, anxiety and depression) by controlling for key variables of mental health and stress research such as critical life events, chronic stressors and social resources in a national sample. Prior studies on emotions have not included these context variables (Simon and Nath 2004; Rackow et al. 2012). Furthermore, the study complements the sociology of social inequality by highlighting the emotional consequences of socioeconomic disadvantages (Gordon 1990). This approach links the external reality of objective socioeconomic conditions and the internal reality of individuals by focusing on emotions.

1.2 The paper is organised as follows. The following section outlines a sociology-of-emotions perspective on the relationship between socioeconomic status and negative emotions. Findings of mental health and stress research can be linked with the theoretical and empirical work on the sociology of emotions. The next section introduces the Swiss Household Panel (SHP) data as well as the variables and the methods used. A random effects regression was applied to analyse socioeconomic status differences in negative emotions. The subsequent section presents the findings before the final section draws conclusions and addresses limitations of the study.

\section{Linking emotions and socioeconomic status}

2.1 Theoretical approaches in the sociology of emotions provide insight into the impact of socioeconomic status positions on negative emotions. This section outlines Kemper's structural theory $(1978,1981,1991)$ that links power and status allocation with the arousal of negative emotions and sketches Collins' (1981) concept of emotional energy. Both approaches conceive of social relationships in terms of the two dimensions of status and power. For Kemper (1981: 338), social structure is a general concept that applies to the macro level (the relationship between categories such as male vs. female, organisation or social classes) and also to the micro level of individual actors in interpersonal relationships. Emotions result from real, anticipated or imagined outcomes of social interactions (Kemper and Collins 1990). Power refers to "actions that are coercing, forcing, threatening, punishing, (...) producing thereby a relationship of domination and control of one actor by the other" (Kemper 1981: 337). The other is overcome and complies involuntarily (Kemper 1991: 332). Status is a 'scalar dimension reflecting the amount of uncoerced, willing compliance, approval, deference, reward, praise, emotional or financial support, even love, that actors accord each other' (Kemper 1981: 337). These classes of situational events (decrements in power or status) and attribution processes stimulate the same emotion. The latter refers to the agent of the outcome, whether a loss or gain of status/power is attributed to the self, to another person or to third parties (Kemper 1991: 333). According to Kemper (1978: 35), depression results from a deficit in status, i.e., an insufficiency of reward and gratification given by others, for example, as experienced in the rejection of one's work. Where the self or third parties are made responsible for a status deficit, classic syndromes appear, such as despair, worthlessness or apathy (Kemper 1978: 36). The core of anxiety, however, lies in an "imbalance in the power relationships between actors, the one with relatively less power is vulnerable to the encroachments of the other" (Kemper 1978: 35). In summary, a loss in one's own power or a gain in power by others evokes anxiety. Particular emotions arise from particular 'social 
relational outcomes' (Kemper 1981: 355). In line with Kemper, Collins (1981) also views social interactions in terms of power and status that produce high or low levels of emotional energy (Kemper and Collins 1990). Emotional energy can be understood as ranging from solidarity, motivation and positive sentiments on the one hand to depression, fear and other negative emotions on the other. Successful interaction rituals can create emotional energy, whereas decreased emotional confidence results from experiencing rejection or lack of success (Collins 1981: 1001-2). The power dimension refers to assuming a dominant position within an interaction, which leads to emotional energy, or taking a subordinate position, which reduces one's emotional energy (Collins 1981: 1002). This dimension primarily refers to the area of work organisation (Kemper and Collins 1990). Status, by contrast, includes situations that involve social inclusion or exclusion and increase or diminish emotional energy (Kemper 1991: 6). One general implication of this account is that "persons with lower status and power experience more negative feelings" (Simon and Nath 2004: 1139).

'Thus, the structure of inequality will correspond to the distribution of positive and negative emotions, with higher-ranking individuals more likely to experience positive emotional arousal than lower-ranking persons, with the result that emotions become yet one more resource distributed unequally' (Turner and Stets 2005: 294).

2.2 Being low educated, unemployed and materially deprived can be understood as manifestations of a low power-status position in accordance with Kemper $(\underline{1978,1981)}$ and Collins (1981). Education and income are general indicators of higher status positions including characteristics such as job authority, power, control and autonomy ( $\underline{\text { Schieman }}$ 2006). Economic hardship often results in experiencing injustice and threats to identity (Schieman 2006). Particularly unemployment can be associated with resignation and depression as the classic Marienthal study (Jahoda et al. 1978) has demonstrated impressively. The authors described the effects at the individual, interpersonal and community level as a state of apathy (Jahoda et al. 1978). In a more recent experimental study, Twenge et al. (2003) have shown that social exclusion leads to a feeling of inner numbness that comes with disordered time perceptions, a sense of futility and passivity. Unemployment is said to produce high rates of intense sadness and depression-like symptoms connected with financial strains and declining prestige, status and resources (MacDonald and Shildrick 2013; Shildrick et al. 2010; Aneshensel 1992). Especially the long-term combination of financial hardship, menial work and unemployment is related to depression and other poor health outcomes among younger adults, as Shildrick et al. (2010) have identified.

2.3 Mental health research has emphasised that higher status positions are associated with personal control and lower positions with powerlessness that leads to demoralisation and hampers effective coping with difficult events or situations (Mirowsky and Ross 1989; Aneshensel 1992; Thoits 2006). In general, low status positions increase the probability of experiencing losses of prestige or control as well as failure to achieve valued goals. These situations have been defined as context-specific sources of sadness (Horwitz and Wakefield 2007). In this regard, Illouz (2007: 73) has highlighted the unequal distribution of emotional competence and psychological knowledge across social positions, establishing 'new hierarchies of emotional well-being'. Emotional competence can be understood as selfawareness or the ability to find solutions to a problem. Positive effects are expected from dealing with the self and social relationships by structuring biographies, handling failures and crisis, or preserving a sense of security (Illouz 2007). Level of education is an important indicator of emotional competence and psychological knowledge. Generally spoken, education increases the ability to meet and solve problems on different levels of operation such as thought, attention, communication or negotiation (Mirowsky and Ross 1989). 
Education can enhance resources such as self-efficacy or mastery (Aneshensel 1992).

Empirical evidence in support of this can be found in bereavement research. For example, the usage of counselling literature correlates with social class, constituting a coping resource primarily for members of the middle class (Allen 2007).

2.4 Psychological and psychiatric research has documented an inverse relation between socioeconomic status and mental disorders or related outcomes (e.g., Murphy et al. 1991; Matthews and Gallo 2011; Ritsher et al. 2001; Gallo and Matthews 2003). However, several studies report that they detected no relationship between SES and depression (for a review, Yu and Williams 2006). Health statistics in Switzerland have documented the correlation between various indicators of socioeconomic status (i.e., educational level, unemployment) and self-reported depressive feelings. Overall, 5.2\% of the Swiss population has been diagnosed with major depression (Swiss Health Observatory 2013). Budowski et al. (2009) have analysed the effects of cumulative disadvantages during youth, such as parental divorce, financial hardship or a low level of parental education, on self-reported psychological health in Switzerland.

2.5 With the exception of Simon and Nath (2004), Rackow et al. (2012) and Jakoby (2013), sociological research on negative emotions drawing on survey data is still rare. In their analysis of the General Social Survey (GSS) 1986, Simon and Nath (2004) found effects of education and income on the frequency of sadness and anxiety. Persons with lower education and household income report feelings of sadness more often than those with higher education and income (Simon and Nath 2004; Simon 2002). Jakoby (2013) reported associations between education, income and the frequency of sadness. Using data from the German SocioEconomic Panel Study (GSOEP), Rackow et al. (2012) found income to have negative effects on anxiety. The association between level of education and anxiety can be attributed to differences in income. Moreover, occupational prestige did not correlate with anxiety; it is rather associated with anger (Rackow et al. 2012; Schieman 2006; Collett and Lizardo 2010).

2.6 Summarising the approaches above, we can think of emotions as an outcome of different allocations of power, status and resources (Turner et al. 1995). This argument follows the social causation hypothesis, which indicates that a low SES level causes psychological distress (Ritsher et al. 2001). Level of education, occupational status and income account for different distributions of status and power, in the sense described by Kemper (1981) leading to different emotional experiences. Furthermore, we have to take into account context factors such as critical life events, chronic stressors or a lack of social resources as proposed by stress and mental health research (Pearlin 1989; Aneshensel 1992; Aneshensel et al. 1991; Kessler 1997; Thoits 2006). Critical life events are significant stressors or 'exogenous shocks' (Ormel et al. 1999) linked with poor mental health. Undesirable life events such as the death of a loved one or divorce are strongly associated with psychological distress. Chronic strains - for example, ongoing interpersonal difficulties, illness, social and economic hardship - are also important social stressors (Pearlin 1989; Aneshensel 1992; Thoits 2006). Social networks (family, friends) are social resources that facilitate coping with demanding events or situations by providing emotional or practical support (Thoits 2006). However, critical life events, chronic stressors as well as social resources are not evenly distributed in society: those of low socioeconomic status are more likely to experience chronic stress and a lack of (personal or social) coping resources (Matthews and Gallo 2011; Turner et al. 1995; Aneshensel 1992; McLeod and Kessler 1990; Thoits 2006). When systematically examining the association between SES and negative emotions, we have to control for these context variables. 
2.7 The aforementioned theoretical approaches and previous empirical findings provided the basis for deriving the four hypotheses listed below. They suggest three distinct effects of education, income and occupational status on the frequency of experiencing negative emotions (desperation, anxiety and depression).

Hypothesis 1: The higher one's education, the less frequent are negative emotions. Hypothesis 2: Unemployment leads to experiencing negative emotions more frequently. Hypothesis 3: The higher one's income, the less frequent are negative emotions. Hypothesis 4: The association between level of education, occupational status, income and negative emotions persists upon controlling for context variables such as critical life events, chronic stressors and social resources.

\section{Data and method}

3.1 The data used in this article are from the Swiss Household Panel (SHP). The principal aim of the Swiss Household Panel (SHP) is to observe social change, in particular the dynamics of changing living conditions and representative characteristics of the population of Switzerland. It is a yearly panel study that follows a random sample of private households in Switzerland over time and interviews all household members mainly by telephone. The SHP constitutes a longitudinal database for Switzerland and is supported by the Swiss National Science Foundation. The survey covers a broad range of topics and approaches in the social sciences. Data collection started in 1999 with a sample of 5,074 households consisting of 12,931 household members. In 2004 a second sample of 2,538 households with a total of 6,569 household members was added; and since 2013 the SHP contains a third sample of 4,093 households and 9,945 individuals. Currently the SHP database holds information for the years 1999 to $2014 .{ }^{[3]}$

3.2 The present study used the seven waves from 2005 to 2011. The SHP data can be classified as a balanced panel. A random effects regression for panel data (xtreg, re command in Stata) was applied. ${ }^{[4]}$ One advantage of the RE-estimator is that it provides estimates for time-invariant variables. It combines within and between variation in the same regression, i.e., $\mathrm{x}$ changes over time and between groups (Verbeek 2008; Bryan 2011). The interpretation of the coefficients includes both the within- and between-effect. The random effects model is written as

$$
y_{i t}=\beta_{0}+\times_{i t} \beta+\alpha_{i}+u_{i t}
$$

where $\beta_{0}$ is the constant, ${ }^{{ }_{i t}}$ the vector for independent variables and $\beta$ represents the estimates for the coefficients. $\alpha_{i}+u_{i t}$ is treated as an error term consisting of two components: an individual specific component, which does not vary over time (individual effect ${ }^{\alpha_{i}}$ ), and a second error term (residuals) ${ }^{u_{i t}}$ (Verbeek 2008: 364). The Breusch-Pagan Lagrange multiplier test (LM) for random effects (xttest0 command in Stata) was applied as a postestimation test for xtreg to ensure that the decision for random effects estimation and against pooled OLS estimation was the proper choice (Wooldridge 2002). The null hypothesis was rejected ( $c h i$ 15704.33, $p \leq .000$ ), indicating that random effects can be considered to be the appropriate model.

3.3 The dependent variable is the frequency of negative emotions (desperation, anxiety and depression), which was measured on a scale from 0 (never) to 10 (always): 'Do you often have negative feelings such as having the blues, being desperate, suffering from anxiety or 
depression?' Socioeconomic status was conceptualised by three traditional indicators that capture resource and prestige components of SES: level of education, occupational status and income. Although correlations among them may exist, these three indicators 'represent distinct socioeconomic information' (Matthews and Gallo 2011: 5). ${ }^{[5]}$ Level of education was coded as $1=$ low (no school, compulsory school education, general upper secondary education) 2=medium (apprenticeship/vocational training, full-time school-based vocational training, university entrance qualification) and $3=$ high (tertiary vocational training, university of applied sciences, university degree). This study is particularly interested in the effect of unemployment. Occupational status was coded as $1=$ active occupied, $2=$ unemployed and $3=$ not in labour force. These variables were included as dummies. Income was measured as net income per year (household) using the OECD equivalence scale. The logarithm of income was used.

3.4 The model was estimated while controlling for key variables used in mental health and stress research and considering critical life events such as death of a close person $(0=$ no, $1=\mathrm{yes})$, end of a close relationship ( $0=$ no, $1=\mathrm{yes})$ as well as chronic stressors (chronic illness $(0=$ no, $1=y e s)$. The number of friends was included as a measure of social resources. Respondents were asked: 'How many good and close friends do you have?' Additional control variables included gender $(0=$ men, $1=$ women $)$ and civil status $(1=$ single, $2=$ married, $3=$ divorced, $4=$ widowed). In the regression analysis, age was employed as a continuous variable. The square of age tested for curvilinear effects. Nationality was coded as $1=$ Swiss, $2=$ Swiss and a second nationality and $3=$ other nationality. Finally, the language regions of Switzerland (1=German, 2=French, 3=Italian) acted as controls. These variables were included as dummies. ${ }^{[6]}$

3.5 To examine the relationship between socioeconomic status and negative emotions, four models were estimated. The control model (Model 1) estimated the effects of gender, age, civil status, nationality and Swiss language regions. Model 2 added educational level and occupational status, whereas Model 3 accounted for income. This analytical strategy was applied to test for possible distinct effects of education and occupation. The aim was to ensure that these indicators do not simply measure income differences. The full model (Model 4) included key variables of stress and mental health (critical life events, chronic stressors, and social resources) to ascertain the association between SES and negative emotions.

\section{Results}

Table 1 presents estimates of the random effects regression for the general sample.

Table 1. Random effects regression on negative emotions 


\begin{tabular}{|c|c|c|c|c|c|c|c|c|c|c|c|c|}
\hline & \multicolumn{4}{|c|}{ Model 1} & \multicolumn{4}{|c|}{ Model 2} & \multicolumn{4}{|c|}{ Model 3} \\
\hline Female & $\begin{array}{r}b \\
.644\end{array}$ & $*$ & $\begin{array}{r}z \\
-14.99\end{array}$ & $\begin{array}{r}\text { S.E. } \\
.043\end{array}$ & $\begin{array}{r}b \\
.605\end{array}$ & $* *$ & $\begin{array}{r}2 \\
-13.87\end{array}$ & $\begin{array}{l}\text { S.E. } \\
.044\end{array}$ & $\begin{array}{r}b \\
.602\end{array}$ & $*$ & $\begin{array}{r}z \\
-13.83\end{array}$ & 5. \\
\hline Age & .020 & + & 2.89 & .007 & .035 & $* *$ & 4.34 & $.08 B$ & .036 & $*$ & 4.52 & $\bar{\alpha}$ \\
\hline Age squared & -.000 & & -1.80 & .000 & -.000 & $*$ & -3.32 & .000 & -.000 & $*$ & -3.46 & $\alpha$ \\
\hline $\begin{array}{l}\text { Oivil stotus (ref. = single) } \\
\text { Married }\end{array}$ & -.279 & $* *$ & -4.84 & .058 & -.286 & $* *$ & -4.98 & .057 & -.299 & $* *$ & -.518 & $0 !$ \\
\hline Divorced & .027 & & 0.29 & .093 & .022 & & 0.24 & .093 & .008 & & 0.08 & 0 \\
\hline Widowed & -.008 & & -0.06 & .131 & -.024 & & -0.18 & .130 & -.044 & & -0.34 & $1:$ \\
\hline $\begin{array}{l}\text { Notionality (ref. }=5 \text { wiss) } \\
\text { 5wiss+other nationality }\end{array}$ & .389 & $* *$ & 5.35 & .073 & .375 & $* *$ & 5.18 & .072 & .375 & $*$ & 5.19 & 0 \\
\hline other nationality & .443 & $*$ & 4.76 & .093 & .410 & $*$ & 4.45 & .092 & .408 & $*$ & 4.43 & 0 \\
\hline $\begin{array}{l}\text { Longuoge region (ref. = German) } \\
\text { French language region }\end{array}$ & .444 & $* *$ & 8.29 & .054 & .438 & $*$ & 8.20 & .053 & .436 & $\bullet$ & 8.16 & $0 !$ \\
\hline Italian language region & .566 & $* *$ & 4.09 & .138 & .550 & $* *$ & 4.00 & .138 & .539 & $*$ & 3.91 & $1:$ \\
\hline $\begin{array}{l}\text { Educotion (ref. = low education) } \\
\text { Medium education }\end{array}$ & & & & & -.219 & $*$ & -3.74 & .059 & -.208 & $\bullet$ & -3.55 & $0:$ \\
\hline High education & & & & & -.274 & $*$ & -4.23 & .065 & -.248 & $*$ & -3.80 & . 0 \\
\hline $\begin{array}{l}\text { Occupotion (ref. = active occupied) } \\
\text { Unemployed }\end{array}$ & & & & & .462 & $*$ & 4.76 & .097 & .452 & $*$ & 4.66 & $.0 !$ \\
\hline Not in labour force & & & & & .047 & & 1.13 & .041 & .038 & & 0.92 & 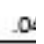 \\
\hline Income & & & & & & & & & -.079 & $*$ & -3.29 & 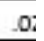 \\
\hline $\begin{array}{l}\text { Death (ref. = no) } \\
\text { End of relationship (ref. = no) } \\
\text { Chronic illness (ref. = no) } \\
\text { Number of friends }\end{array}$ & & & & & & & & & & & & \\
\hline Constant & 1.654 & $*$ & 10.92 & .151 & 1.521 & $*$ & 9.53 & .160 & 2.339 & $*$ & 7.92 & $2 !$ \\
\hline$N$ & 27,377 & & & & 27,377 & & & & 27,377 & & & \\
\hline$R^{2}$ within & 0.0003 & & & & 0.0007 & & & & 0.0007 & & & \\
\hline$R^{2}$ between & 0.0777 & & & & 0.0870 & & & & 0.0893 & & & \\
\hline$R^{2}$ total & 0.0555 & & & & 0.0620 & & & & 0.0640 & & & \\
\hline
\end{tabular}

Notes: " $p<0.05, * 0<0.01$; Reference categaries in parentheses.

Source: SHP 2005-2011, my own calculations.

4.1 Model 1 reveals significant effects of gender, age, civil status, nationality and Swiss language regions on the frequency of negative emotions. Women, other nationalities (reference category: Swiss) and French- or Italian-speaking parts of Switzerland report desperation, anxiety and depression more frequently, whereas married persons (reference category: single) report negative emotions less frequently. The positive linear effect of age and the negative effect of age squared indicate a curvilinear effect on negative emotions.

4.2 Model 2 shows that persons with medium and high education report negative emotions less frequently, which supports Hypothesis 1. Another notable result is the effect of unemployment on the frequency of desperation, anxiety and depression. Unemployed persons report negative emotions more frequently than those active occupied, which indicates the validity of Hypothesis 2. As predicted in Model 3, income has a negative effect; the lower the income, the more frequent are negative emotions. This finding supports Hypothesis 3.

Furthermore, income accounts for a slight decrease in the coefficients for education. The effect drops from - .219 to -.208 (medium education) and - .274 to -.248 (high education) when controlling for income. This slight reduction in effect suggests a distinct effect of education on the frequency of negative emotions. However, the decrease in effect size is somewhat larger for the highly educated. The effect of unemployment slightly drops from .462 to .452 when controlling for income. This result indicates a distinct effect of unemployment on negative emotions. In an alternative model and separate analysis not shown here, the effect of occupational prestige on desperation, anxiety and depression, as measured by Goldthorpe's class schema, was non-significant. Previous research suggests that occupational prestige is associated with anger (Rackow et al. 2012; Collett and Lizardo 2010). 
4.3 Controlling for context variables in the full model, such as death of a close person, end of a close relationship, chronic illness as well as the number of friends, has no impact on the SES variables. The inclusion of key mental health and stress research variables does not alter the association between SES and negative emotions. This is clear evidence in support of Hypothesis 4. It is worthwhile to note the significant effect of being integrated in social networks. The less close friends one has, the more frequent are negative emotions.

Furthermore, Model 4 shows that critical life events and chronic illness have significant effects on the frequency of negative emotions.

4.4 When all variables are considered simultaneously, the relationship between the control variables gender, age, civil status, nationality, Swiss language region and negative emotions remain stable. The gender-effect is consistent with previous research on emotions (Simon and Nath 2004; Rackow et al. 2012) as well as research on mental health and gender (e.g., Simon 2002; Simon and Lively 2010). The finding also corresponds with Simon and Nath's (2004) observation of gender-specific rates of sadness, which hold after controlling for socioeconomic status. Socioeconomic status differences cannot completely account for gender-specific variations in negative emotions as implied by Kemper (1981). Model 3 shows that the gender effect drops from -.644 to -.602 when controlling for level of education, occupational status and income.

4.5 Table 2 reports the results of the random regression that was estimated separately for female and male respondents to account for gender-specific effects of socioeconomic status.

Table 2. Random effects regression for female and male respondents

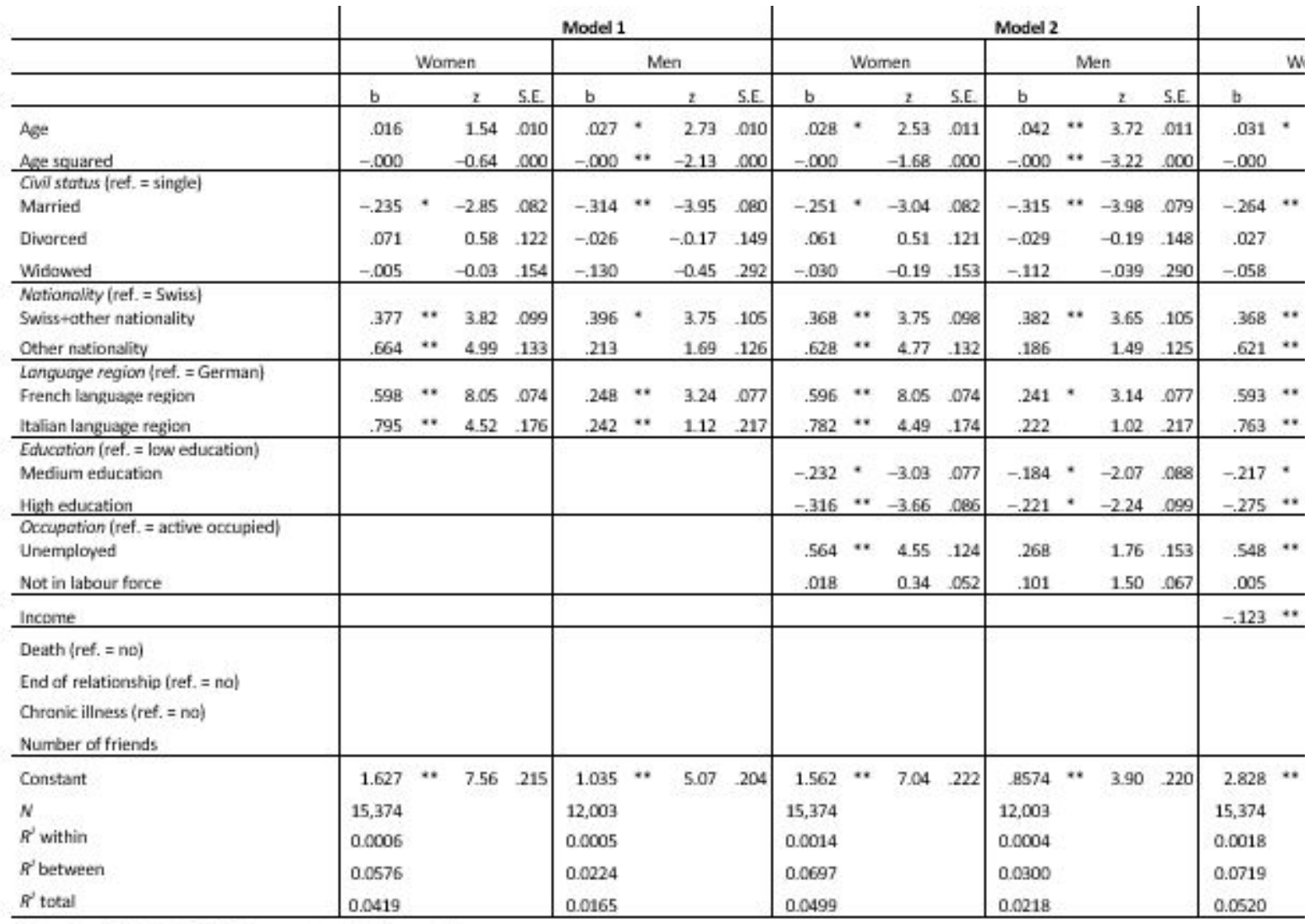

Notes: " $p<0.05$; " $p<0.01$, Reference cateparies in parentheses.

Sounce: SHP 2005-2011, my own caiculations. 


\begin{tabular}{|c|c|c|c|c|c|c|c|c|}
\hline & \multicolumn{8}{|c|}{ Model 4} \\
\hline & \multicolumn{4}{|c|}{ Women } & \multicolumn{4}{|c|}{ Men } \\
\hline & b & & $z$ & S.E. & b & & 2 & S.E. \\
\hline Age & .028 & * & 2.55 & 011 & 042 & $*$ & 3.79 & 011 \\
\hline Age squared & -.000 & & -1.92 & .000 & -.000 & $*$ & -3.46 & .000 \\
\hline \multicolumn{9}{|l|}{ Civil stutus fref. $=$ single) } \\
\hline Married & -.220 & $*$ & -2.72 & $\cos 1$ & -.299 & $*$ & -3.82 & .078 \\
\hline Divarced & .018 & & 0.16 & .117 & -.069 & & -0.47 & .146 \\
\hline Widawed & -.044 & & -0.02 & .150 & -.032 & & -0.11 & .275 \\
\hline \multicolumn{9}{|l|}{ Notianality (ref. = Swiss) } \\
\hline Swiss+ather nationality & .354 & $*$ & 3.73 & $\cos$ & .363 & $*$ & 3.59 & .101 \\
\hline Qther nationality & 599 & $*$ & 4.71 & .127 & .191 & & 1.56 & .123 \\
\hline \multicolumn{9}{|l|}{ Language region \{ref. = German\} } \\
\hline French language region & 640 & $*$ & 8.83 & .072 & .263 & $*$ & 3.50 & .075 \\
\hline Italian language region & .789 & $*$ & 4.54 & .174 & .269 & & 1.26 & .213 \\
\hline \multicolumn{9}{|l|}{ Echucation (ref. = low education) } \\
\hline Medium education & -.207 & * & -2.77 & .075 & -.178 & - & -2.03 & .068 \\
\hline High education & -249 & . & -2.94 & coss & -.218 & * & -2.22 & .098 \\
\hline \multicolumn{9}{|c|}{ Occupatian (ref. = active occupied) } \\
\hline Unemployed & .533 & $*$ & 4.35 & .123 & .280 & & 1.82 & .154 \\
\hline Not in labour force & .010 & & 0.51 & .019 & .077 & & 1.17 & .066 \\
\hline Income & -120 & $*$ & -3.62 & .033 & -.021 & & -0.63 & .036 \\
\hline Death $($ ref. $=$ no) & .043 & & 1.44 & .030 & .068 & * & 2.91 & .030 \\
\hline End of relationship (ref. $=$ no) & 340 & $*$ & 5.54 & .061 & .348 & $*$ & 5.46 & .064 \\
\hline Chronic illness $(r e f .=$ na) & .429 & $*$ & 11.65 & .037 & .371 & $*$ & 9.22 & .040 \\
\hline Number of friends & -.017 & $*$ & -3.75 & .005 & -.007 & * & -2.15 & .003 \\
\hline Constant & 2.783 & $*$ & 694 & 401 & 1.007 & $*$ & 8.07 & .286 \\
\hline$N$ & 15,374 & & & & 12,003 & & & \\
\hline$R^{\prime}$ within & 0.0068 & & & & 0.0055 & & & \\
\hline$R^{\prime}$ between & 0.1315 & & & & 0.0979 & & & \\
\hline$\tilde{R}^{\prime}$ total & 0.0907 & & & & 0.0635 & & & \\
\hline
\end{tabular}

Notes: " $p<0.05 ; " p \times 0.01$, Reference cuteqaries in parentheses.

Sounce: SHP 2005-2011, my own caiculations.

4.6 Auxiliary interactional analysis of the general model (not shown here) revealed that the negative effect of income on negative emotions is significantly greater for women. When we focus on socioeconomic status, Model 2 and Model 3 reveal interesting differences in the effects for women and men. Whereas education, unemployment and income have significant effects on negative emotions of women, only one effect of education can be identified for men. Men with medium and high education report negative emotions less frequently than men with low education. By contrast, income and occupational status have no statistically significant effects. Model 3 shows that the education effect for female respondents slightly drops from - .232 to -.217 (medium education) and -.316 to -.275 (high education) when controlling for income. However, income can explain part of the effect of the coefficient for high education. The effect of unemployment slightly drops from .564 to .548 when controlling for income. As noted before, these results suggest three distinct effects of education, occupation and income on the frequency of negative emotions among women. It is interesting to note that low income and unemployment are not linked with desperation, anxiety and depression reported by men. Controlling for context variables in the full model has no impact on these associations.

\section{Conclusions}

5.1 On the basis of Swiss Household Panel (SHP) data for the period from 2005-2011, the random effects regression assessed relationships between the frequency of negative emotions and the parameters of individual socioeconomic status. Contrary to previous studies on mental disorders, the analysis is based on everyday subjective feelings as measured in a national sample (Thoits 1989). The analyses revealed distinct effects of education, income and unemployment on the frequency of negative emotions. These associations remain stable and 
persist upon controlling for key variables discussed in mental health and stress research such as critical life events, chronic illness or social networks. The findings suggest that level of education, occupational status and income account for differences in the allocation of power and status in accordance with Kemper $(1978,1981)$ and Collins $(1981)$. Education must be regarded as a key resource for emotional well-being, for example in terms of psychological knowledge (Illouz 2007, 2008). Low income and unemployment are also linked to more frequent feelings of anxiety, desperation and depression. However, the effect of unemployment should not be understood solely in terms of economic deprivation. Job loss can impair status, power, prestige and the identity of individuals as well (Shildrick et al. 2010). Therefore the findings emphasise the timeliness of the classic Marienthal study (Jahoda et al. 1978), which showed the state of apathy to be a major consequence of unemployment. Unemployment bears the potential for "exclusion from full participation in the social system" (Aneshensel 1992: 34), and anxiety, desperation and depression can be interpreted as emotional outcomes to this exclusion. Conversely, employment must be regarded as an important 'socioenvironmental factor for emotional functioning' (Aneshensel 1992: 30). In the face of the current EU financial crisis, which has come with high unemployment rates predominantly in Southern Europe, this finding sheds critical light on the emotional consequences of job loss for those affected.

5.2 Overall, the results confirm previous studies on SES and mental health or specific emotions such as anxiety or depression (e.g., Mirowsky and Ross 1989; Simon and Nath 2004; Rackow et al. 2012). Structurally conditioned inequalities lead to emotional inequalities in a society: the lower one's position in the social power and status structure, the more likely are chronic experiences of negative, low arousing emotions (e.g. anxiety, sadness, apathy) independent of critical life events or coping resources. Yet the impact of financial hardship and unemployment on desperation, anxiety and depressive feelings differs between men and women. The results suggest that women tend to internalise stressful situations (material deprivation, unemployment), which leads to negative emotions. Research on men and depression (e.g., Oliffe and Phillipps 2008; Ogrodniczuk and Oliffe 2011) has shown that men tend to externalise stress instead of verbally communicating emotions. In line with the gendered-response hypothesis, male depression does not become manifest at the emotional level but finds expression in substance misuse, anger or aggression instead (e.g., Mirowsky and Ross 1995; Simon and Lively 2010; Ogrodniczuk and Oliffe 2011). Self-reports presuppose awareness and transparency of subjective feelings (Ahmed 2012). Against the background of gender-specific feeling and display rules (Hochschild 1979, 1983), according to which women are more likely to talk openly about feeling sad or report symptoms of depression, anxiety and sadness can be regarded as 'feminine emotions' (Brody 1997) reflecting socialised norms about legitimate feelings as well as unequal social and economic roles (Hopcroft and Bradley 2007). Emotions are always social and historical constructs, as Ahmed $(2010,2012)$ has demonstrated for happiness. ${ }^{[7]}$ However, in the course of the changing ideals, roles and norms of masculinity, one could assume greater emotional awareness and the acknowledgement of feelings of sadness as a disposition appropriate to younger men in the future as well. Yet further research into the emotional consequences of low male status positions is needed.

5.3 In line with these arguments, the results also indicate possible cultural differences in interpreting and responding to questions about negative emotions. People living in the Frenchand Italian-speaking parts of Switzerland report desperation, anxiety and depression more frequently. These differences cannot be explained by socioeconomic status. In contrast, different 'emotional cultures' (Gordon 1990: 146), including specific norms or beliefs in regard to emotions, might account for this finding. It is possible that higher emotional 
expressivity in French- or Italian-speaking Switzerland compared to the German-speaking parts of the country explain this relationship. Another explanation refers to the French- and Italian-speaking Swiss population being more oriented toward and having a stronger sense of belonging to the neighbouring countries of France and Italy respectively. This can lead to a more distanced relationship to German-speaking Switzerland and feelings of exclusion and alienation in one's own country as a consequence of being in such a minority position (Jakoby 2013). Further research is needed to understand the association between the Swiss language regions and the distribution of negative emotions.

5.4 The research presented here also has limitations, which need to be discussed. First, there are several methodological issues related to the dependent variable. The SHP data integrated the experience of three emotional states such as desperation, anxiety and depression into a single question. Future research should discriminate between anxiety and depression and focus on specific emotions and, for example, different age effects on these emotions (Mirowsky and Ross 1989). Technically speaking, it is impossible to differentiate between inner feelings and the communication of these emotions. Only the latter can be measured by self-reports in general social surveys. Self-reports may be affected by display rules and social desirability (Hochschild 1983; Thoits 1989). However, drawing on von Scheve (2013), we can assume that these norms largely correspond with unconscious affects. Moreover, the analysis is restricted to the frequency of emotions, whereas the SHP data does not provide any information on the intensity of negative emotions. Second, key elements of emotions are perceptions and appraisals of situational objects and events (Turner and Stets 2005). In this perspective, it is subjective interpretations of inequality and cognitive appraisals of status, power or resource allocations that elicit negative emotions. With regard to Switzerland ${ }^{[8]}$, we could assume that this could lead to a generally lower awareness of social inequality in the face of socioeconomic prosperity. Lucchini et al. (2014) have stated that 'material deprivation may appear a statistically insignificant and socially invisible phenomenon' in Switzerland. Nevertheless, perceptions of relative income or unemployment in a country with high material living standards as well as high living expenses such as Switzerland may affect the occurrence of feelings of depression and anxiety. Feelings of exclusion and inferiority resulting in negative emotions could be the outcome of subjective definitions of lower-ranking individuals in an affluent society. However, we can only speculate on these theoretical mechanisms because the use of secondary data does not allow a more thorough exploration thereof (for similar arguments, see Rackow et al. 2012). Experimental methods would be one possible direction for further research on unobservable cognitive appraisals.

5.5 Why is it important to know about emotional inequality? First, social hierarchies produce emotional hierarchies and vice versa. A poor emotional condition has negative effects on the possibility of participating in society: it is a disintegrating factor. Whereas anger often sparks motivation and activity for change or rebellion, anxiety and depression may lead to passivity, resignation or social withdrawal of lower-status individuals (Rackow et al. 2012; Schieman 2006; Fields et al. 2006). Consequently, an unequal distribution of emotional states can contribute to the reproduction of existing social conditions by driving or stifling the potential for action and social mobility (Collins 1981). Thus, emotional experiences are embedded in contemporary "therapeutic culture" (Illouz 2008). The medical category of 'depression' masks social inequality and structural reasons for sadness or anxiety. Instead of addressing deeper causes, technical remedies along the lines of medical-pharmaceutical interventions or psychiatric counselling are offered; an approach that results in an 'individualisation of social problems' (Conrad 2007) as well as the stigmatisation of individuals as mentally ill. Moreover, studies have documented the relationship between parental depression and depression in their offspring (e.g. Ritsher et al. 2001). Psychological research has also 
discussed the intermediate role of negative emotions (anxiety, depression) in connecting SES with health outcomes (Gallo and Matthews 2003; Matthews and Gallo 2011). In particular, consequences of class-based inequalities among socioeconomic disadvantaged young adults have negative effects on health outcomes and education and employment careers (MacDonald and Shildrick 2013).

5.6 Whereas Horwitz (2013) has diagnosed an 'age of anxiety' and Ehrenberg (2010) has claimed depression to be a typical emotion in contemporary society, the results of this study specify these global assessments. Anxiety, desperation and depression are the characteristic emotions of less-educated, poor and unemployed persons, in short, of the disadvantaged among the Swiss population. These social facts often remain unnoticed in scientific and media discourses on social inequality. The emotional condition cannot be separated from the economic condition.

\section{Notes}

${ }^{1}$ This study has used data collected by the Swiss Household Panel (SHP) based at the Swiss Foundation for Research in Social Sciences FORS, University of Lausanne. The survey is financed by the Swiss National Science Foundation.

${ }^{2}$ Irrespective of the fact that the literature distinguishes between emotion and feeling because of the lower level of awareness involved in emotions (Turner and Stets 2005), the two terms are used synonymously here. In line with Turner and Stets (2005), I understand emotion as an overarching concept that includes other phenomena such as 'feelings' as well.

${ }^{3}$ http://forscenter.ch/en/our-surveys/swiss-household-panel/, retrieved on 9th November 2014.

${ }^{4}$ The option 'robust' was added to control for heteroscedasticity.

${ }^{5}$ Studies that used multiple measures of SES were best able to capture health implications (Matthews and Gallo 2011: 4-5). Furthermore, Hauser and Warren (1997) have questioned the validity and reliability of socioeconomic indexes of occupational prestige. Both authors have argued that the global use of composite indexes of socioeconomic status is scientifically obsolete (Hauser and Warren 1997: 177).

${ }^{6}$ Due to non-applicability after random effects regression, the VIF (variance inflation factor) command in Stata was used after the linear regression model to check for multicollinearity (pooled OLS). A variable whose VIF values are greater than 10 may merit further investigation. The results show acceptable values for all independent variables.

${ }^{7}$ For the history of anxiety and depression, see Horwitz (2013) and Horwitz and Wakefield (2007).

${ }^{8}$ Switzerland has a stable economy, a low unemployment rate and has achieved one of the highest per capita incomes in the world (unemployment rate (2015): 3.3\%, gross domestic product (GDP) per capita (2013): 78,432 Swiss Francs). See Swiss Federal Statistical Office: http://www.bfs.admin.ch/bfs/portal/de/index/themen/03/03/blank/key/registrierte_arbeitslose/ entwicklung.html, 
http://www.bfs.admin.ch/bfs/portal/de/index/themen/04/02/01/key/bip_einw.html (retrieved on 21st January 2016).

\section{References}

ALLEN, C (2007) The Poverty of Death: Social Class, Urban Deprivation, and the Criminological Consequences of Sequestration of Death. Mortality, Vol. 12, No 1, p. 79-93. AHMED, S (2010) The Promise of Happiness. Durham and London: Duke University Press.

AHMED, S (2012) Social Happiness in Spencer D, Walby K and Hunt A (Eds.) Emotions Matter. A relational approach to emotions. Toronto: University of Toronto Press.

ANESHENSEL, CS (1992) Social Stress: Theory and Research. Annual Review of Sociology, Vol. 18, p. 15-38. [doi:10.1146/annurev.so.18.080192.000311]

ANESHENSEL CS, Rutter CM and Lachenbruch LA, (1991) Social Structure, Stress, and Mental Health: Competing Conceptual and Analytic Models. American Sociological Review, Vol. 56, No. 2, p.166-178. [doi:10.2307/2095777]

BRODY, LR (1997) Gender and Emotion: Beyond Stereotypes. Journal of Social Issues, Vol. 53, No. 2, p. 369-394. [doi:10.1111/j.1540-4560.1997.tb02448.x]

BRYAN, M (2011) Panel Data Analysis of Microdata. University of Essex.

BUDOWSKI M, Massia M and Tillmann R, (2009) Psychological Health: an Analysis fo the Intersection of Cumulative Disadvantage and Partnership Events, Swiss Journal of Sociology, Vol. 35, No. 2, p. 357-376.

COLLETT JL and Lizardo O, (2010) Occupational Status and the Experience of Anger. Social Forces 88(5): p. 2079-2104. [doi:10.1353/sof.2010.0037]

COLLINS, R (1981) On the Microfoundations of Macrosociology. American Journal of Sociology, Vol. 86, No. 5, p. 984-1014. [doi:10.1086/227351]

CONRAD, P (2007): The medicalization of society. On the transformation of human conditions in treatable disorders. Baltimore: The John Hopkins University Press.

EHRENBERG, A (2010) The Weariness of the Self. Diagnosing the History of Depression in Contemporary Age. Quebec: McGill-Queen's University Press.

FIELDS J, Copp M and Kleinman S, (2006) Symbolic Interactionism, Inequality, and Emotions in Stets JE and Turner JA (Eds.) Handbook of the Sociology of Emotions. New York: Springer. [doi:10.1007/978-0-387-30715-2_8]

GALLO LC and Matthews KA, (2003) Understanding the Association Between Socioeconomic Status and Physical Health: Do Negative Emotions Play a Role? Psychological Bulletin, Vol. 129, No. 1, p. 10-51. [doi:10.1037/0033-2909.129.1.10] 
GORDON, SL (1990) Social Structural Effects on Emotions in KEMPER TD (Ed.) Research Agendas in the Sociology of Emotions. New York: State University Press.

HOCHSCHILD, AR (1979) Emotion work, feeling rules and social structure, American Journal of Sociology, Vol. 85, p. 551-575. [doi:10.1086/227049]

HOCHSCHILD, AR (1983) The Managed Heart. Commercialization of Human Feeling. Berkeley/Los Angeles/London: University of California Press.

HOPCROFT RL and Bradley DB, (2007) The Sex Difference in Depression Across 29

Countries, Social Forces, Vol. 85, No. 4, p. 1483-1507. [doi:10.1353/sof.2007.0071]

HORWITZ, AV (2013) Anxiety: A Short History. Baltimore: Johns Hopkins University Press.

HORWITZ AV and Wakefield JC, (2007) The Loss of Sadness. How Psychiatry Transformed Normal Sorrow Into Depressive Disorder. Oxford: Oxford University Press.

ILLOUZ, E (2007) Cold Intimacies. The Making of Emotional Capitalism. Malden, MA: Polity Press.

ILLOUZ, E (2008) Saving the Modern Soul: Therapy, Emotions, and the Culture of Self-Help. Berkeley and Los Angeles: University of California Press.

JAHODA M, Lazarsfeld PF and Zeisel H, (1978) Marienthal. The Sociography of an Unemployed Community. Chicago: Aldine.

JAKOBY, N (2013) Die gesellschaftliche Verteilung von Traurigkeit. Eine emotionssoziologische Analyse [The Societal Distribution of Sadness. A Sociology of Emotions Perspective]. Österreichische Zeitschrift für Soziologie, Vol. 38, No. 1, p. 33-53. [doi:10.1007/s11614-013-0068-4]

KEMPER, TD (1991) Predicting Emotions from Social Relations. Social Psychology Quarterly, Vol. 54, No. 4, p. 330-342. [doi:10.2307/2786845]

KEMPER, TD (1981) Social Constructionist and Positivist Approaches to the Sociology of Emotions. American Journal of Sociology, Vol. 87, No. 2, p. 336-362. [doi:10.1086/227461]

KEMPER, TD (1978) Toward a Sociology of Emotions: Some Problems and Some Solutions. The American Sociologist, Vol. 13, No. 1, p. 30-41.

KEMPER TD and Collins R, (1990) Dimensions of Microinteraction. American Journal of Sociology, Vol. 96, No. 1, p. 32-68. [doi:10.1086/229492]

KESSLER, RC (1997) The Effects of Stressful Life Events on Depression. Annual Review of Psychology, Vol. 48, p. 191-124. [doi:10.1146/annurev.psych.48.1.191]

LUCCHINI M, Butti C, Assi J, Spini D and Bernardi L, Multidimensional Deprivation in Contemporary Switzerland Across Social Groups and Time, Sociological Research Online, Vol. 19, No 1 3, http://www.socresonline.org.uk/19/1/3.html. 
MACDONALD R and Shildrick T, (2013): Youth and wellbeing: experiencing bereavement and ill health in marginalised young people's transitions, Sociology of Health and Illness, Vol. 35, No. 1, p. 147-161. [doi:10.1111/j.1467-9566.2012.01488.x]

MATTHEWS KA and Gallo LC, (2011) Psychological Pathways Linking Socioeconomic Status and Physical Health. Annual Review of Psychology, Vol. 62, p. 501-530.

[doi:10.1146/annurev.psych.031809.130711]

MCLEOD J and Kessler RC, (1990) Socioeconomic Status Differences in Vulnerability to Undesirable Life Events. Journal of Health and Social Behavior, Vol. 31, No. 2, p. 162-172. [doi:10.2307/2137170]

MIROWSKY J and Ross CE, (1995) Sex Differences in Distress: Real or Artifact? American Sociological Review, Vol. 60, No. 3, p. 449-468. [doi:10.2307/2096424]

MIROWSKY J and Ross CE, (1989) Social Causes of Psychological Distress. New York: Aldine de Gruyter.

MIROWSKY J and Ross CE, (1986) Social Patterns of Distress. Annual Review of Sociology, Vol. 12, p. 23-45. [doi:10.1146/annurev.so.12.080186.000323]

MURPHY JM, Olivier DC, Monson RR, Sobol AM, Federman EB and Leighton AH, (1991) Depression and Anxiety in Relation to Social Status: A Prospective Epidemiologic Study. Archives of General Psychiatry, Vol. 48, No. 3, p. 223-229.

[doi:10.1001/archpsyc.1991.01810270035004]

OLIFFE JL and Phillips MJ, (2008) Men, depression and masculinities: a review and recommendations, Journal of Mens Health, Vol. 5, No. 3, p. 194-202.

[doi:10.1016/j.jomh.2008.03.016]

ORMEL J, Lindenberg S, Steverink N and Verbrugge LM, (1999) Subjective Well-being and Social Production Functions. Social Indicators Research, Vol. 46, p. 61-90.

[doi:10.1023/A:1006907811502]

OGRODNICZUK JS and Oliffe JL, (2011) Men and depression, Canadian Family Physician, Vol. 57, p. 153-155.

PEARLIN, LI (1989). The Sociological Study of Stress. Journal of Health and Social Behavior, Vol 30, No. 3, p. 241-256. [doi:10.2307/2136956]

RACKOW K, Schupp J and von Scheve C, (2012) Angst und Ärger: Zur Relevanz emotionaler Dimensionen sozialer Ungleichheit [Anxiety and Anger. On the Emotional Dimensions of Social Inequality]. Zeitschrift für Soziologie, Vol. 41, No. 5, p. 392-409. [doi:10.1515/zfsoz-2012-0505]

RITSHER JEB, Warner V, Johnson JG and Dohrenweid BP, (2001) Inter-generational Longitudinal Study of Social Class and Depression: A Test of Social Causation and Social Selection Models. The British Journal of Psychiatry, Vol. 178, p. 84-90.

[doi:10.1192/bjp.178.40.s84] 
SCHIEMAN, S (2006) Anger in Stets JE and Turner JH (Eds.) Handbook of the Sociology of Emotions. New York: Springer. [doi:10.1007/978-0-387-30715-2_22]

SHILDRICK T, MacDonald R, Webster C and Garthwaite K, (2010) The Low-Pay, No-Pay Cicle. York: Joseph Rowntree Foundation.

SIMON, RW (2002) Revisiting the Relationships Among Gender, Marital Status, and Mental Health. American Journal of Sociology, Vol. 107, No. 4, p. 1065-1096. [doi:10.1086/339225]

SIMON RW and Lively K, (2010) Sex, Anger and Depression. Social Forces, Vol. 88, No. 4, p. 1543-1568. [doi:10.1353/sof.2010.0031]

SIMON RW and Nath LE, (2004) Gender and Emotion in the United States: Do Men and Women differ in Self-Reports of Feelings and Expressive Behavior? American Journal of Sociology, Vol. 109, No. 5, p. 1137-1176. [doi:10.1086/382111]

SWISS HEALTH OBSERVATORY, (Ed.) (2013) Depressionen in der Schweizer Bevölkerung. Daten zur Epidemiologie, Behandlung und sozial-beruflichen Integration. Neuchâtel: Schweizerisches Gesundheitsobservatorium.

THOITS, PA (2006) Sociological Approaches to Mental Illness in Aneshensel CS and Phelan JC (Eds.) Handbook of the Sociology of Mental Health. New York: Springer.

THOITS, PA (1989) The Sociology of Emotions. Annual Review of Sociology, Vol. 15, p. 317-342. [doi:10.1146/annurev.so.15.080189.001533]

TURNER JH and Stets JE, (2005). The Sociology of Emotions. Cambridge: Cambridge University Press. [doi:10.1017/CBO9780511819612]

TURNER RJ, Wheaton B and Lloyd DA, (1995) The Epidemiology of Social Stress. American Sociological Review, Vol. 60, No. 1, p. 104-125. [doi:10.2307/2096348]

TWENGE JM, Catanese KR and Baumeister RF (2003) Social Exclusion and the Deconstructed State: Time Perception, Meaninglessness, Lethargy, Lack of Emotion and SelfAwareness. Journal of Personality and Social Psychology, Vol. 85, No. 3, p. 409-423. [doi:10.1037/0022-3514.85.3.409]

VERBEEK, M (2008) A Guide to Modern Econometrics. West Sussex: John Wiley \& Sons.

VON SCHEVE, C (2013) Emotions and Social Structures. The Affective Foundations of Social Order. Frankfurt am Main: Campus.

HAUSER RM and Warren JR, (1997) Socioeconomic Indexes for Occupations: A Review, Update, and Critique. Sociological Methodology, Vol. 27, No. 1, p. 177-298.

[doi:10.1111/1467-9531.271028]

WOOLDRIGDE, JM (2002) Econometric Analysis of Cross Section and Panel Data. Cambridge, MA: MIT Press. 
YANG, Y (2008) Social Inequalities in Happiness in the United States, 1972 to 2004: An Age-Period-Cohort Analysis. American Sociological Review, Vol. 73, No. 2, p. 204-226. [doi:10.1177/000312240807300202]

YU, Y and Williams DR, (2006) Socioeconomic Status and Mental Health in Aneshensel CS and Phelan JC (Eds.) Handbook of the Sociology of Mental Health. New York: Springer. 